\title{
Experiências de Inclusão em Sala de Aula: A Narrativa de uma professora no cotidiano da Práxis
}

\section{School inclusion experiences inside the classroom: The narrative of a teacher in the daily working praxis}

\author{
Daiane Leal da Silva (daiane_kssino@hotmail.com) \\ EMEF. Prof. João de Oliveira Martins \\ Ida Letícia Gautério da Silva (idaquimica@gmail.com) \\ EMEF. Prof. João de Oliveira Martins \\ Jorge Antônio de Oliveira Satt (jorginhosatt@yahoo.com.br) \\ EMEF. Prof. João de Oliveira Martins
}

\begin{abstract}
Resumo: Esta narrativa traz a experiência de uma professora no contexto de sala de aula dos Anos Iniciais, em uma escola pública, situada na periferia da cidade de Rio Grande/RS, durante o ano de 2019. Esta escrita traz problematizações referentes ao planejamento, a partir da reflexão do papel do professor que por vezes necessita ter um olhar sensível para cada estudante e para que as ações na sala de aula incluam todos como sujeitos do seu processo de aprendizagem. Justifica-se a relevância desta escrita por compreender que a sala de aula é cada vez mais diversa e a prática pedagógica necessita de um olhar acolhedor e respeitoso para as diferentes necessidades e potencialidades dos estudantes para que a inclusão se efetive no espaço escolar. Além disso, esta reflexão busca compreender as políticas públicas que garantam seus direitos. Trazemos para o diálogo Vasconcellos (2004), Freire (1996), Cadernos do PNAIC (2015), entre outros autores.
\end{abstract}

Palavras-chave: planejamento; práxis; inclusão.

Abstract: This narrative brings the background experience from a teacher in a primary school located in the outskirts of Rio Grande/RS, during the year of 2019. This reading brings issues related to classroom planning classes, exposing a reflexion along the teacher's role and how they need to have a sensitive and fresh perspective to include all the students into the learning process. It explains the need of having a respectful attention to the specifc needs and development potential of students with the aim to accomplish the school inclusion in the learning environment. In addition, it is of extremely importance to comprehend the public policies in order to have rights guaranteed by law. This reading is based on some well-known authors such as Vasconcellos (2004), Freire (1996), PNAIC bibliografy (2015) among others.

Keywords: planning, praxis, inclusion. 


\section{PRIMEIRAS PALAVRAS}

Esta escrita conta a prática de uma professora em uma turma de $4^{\circ}$ Ano, no ano letivo de 2019. Trago neste texto a parceria com os autores, professores Jorge Satt e Ida Letícia, que exercem a função de Diretor e Vice Diretora, da escola, na qual atuo e que contribuem com minhas reflexões, indagações, inquietudes enquanto professora.

Sou regente de classe desde 2011, na EMEF Professor João de Oliveira- Rio Grande/RS, onde atuo com as turmas de $1^{\circ}$ e $5^{\circ}$ ano dos Anos Iniciais.

Ao longo dos anos que tenho trabalhado como docente eu percebo que as turmas não são mais homogêneas, ou seja, temos sujeitos diferentes em diferentes níveis de aprendizagem, precisando portanto que nós educadores tenhamos um olhar mais singular para cada aluno. Tarefa essa que é desafiadora, pois a partir do momento que percebo essa diferença, no nível de aprendizagem em que as crianças se encontram, é imprescindível que haja uma profunda modificação na prática pedagógica.

Ao falar em prática pedagógica, é necessário apontar para o planejamento. É preciso pensar o planejamento de uma de maneira que inclua todos os estudantes em sala de aula, todos como sujeitos do seu processo de aprendizagem. Mas, nessa tarefa só se terá êxito quando também se fizer o exercício de reflexão critica sobre a prática educativa.

Nesses meus quase nove anos de docência, muito já modifiquei a minha prática pedagógica. Porém esse processo só foi possível quando fiz o exercício da práxis, e entendi que era preciso múltiplos planejamentos para dar conta da singularidade existente nas minhas salas de aula.

A experiência que tenho mais recentemente foi com Curupira; chamo-o assim para reservar sua identidade; alunou do $3^{\circ}$ ano, que estava no inicio do processo de alfabetização fazendo parte de uma turma em que muitos já estavam lendo e escrevendo. Esse aluno precisava que eu trouxesse para ele uma planejamento a parte, que desse conta da sua alfabetização. Foi o que fiz, ao longo do ano letivo, fui trazendo atividades de alfabetização, como de ler e escrever palavras, de escrita espontânea, como seu próprio nome e dos colegas e, com muito incentivo, tivemos sucesso e ele aprovou. Apostar num segundo planejamento apontou caminhos e certezas! 
Nesses meus anos de docência, venho percebendo a importância de se observar a turma, (re) pensar o planejamento, potencializar as aprendizagens das crianças, exercícios esses que exigem muito de um professor comprometido com sua prática pedagógica.

Mesmo com tantas reflexões e clareza da minha profissão professora, em 2019 foi à primeira vez que tive um aluno que me fez ressignificar a docência, pois recebo na minha turma de $4^{\circ}$ ano um aluno com indicativo de transtorno opositor desafiador. Que desafio!

Vou chamá-lo de Minecraft. A escolha deste codinome se deu pelo fato de o aluno apresentar grande interesse pelo jogo e trazer diariamente em seu material um livro com atividades sobre este jogo e que muitas vezes servia para iniciar as atividades em sala de aula e até mesmo facilitava a socialização com seus colegas.

Além de partilhar com vocês essa experiência tão nova pra mim, também farei uma análise dessa prática, finalizando com observações e reflexões a partir do que vivenciei, trazendo para o diálogo os autores como Paulo Freire, Celso Vasconcellos dentre outros.

\section{MINECRAFT: UM ALUNO, UMA PRÁTICA PEDAGÓGICA, MUITO A} CONTAR.

O relato que será aqui partilhado se dá no âmbito da EMEF. Prof. João de Oliveira Martins, localizada na periferia/zona oeste, da cidade do Rio Grande/RS, na turma do $4^{\circ}$ Ano A e que envolve a aprendizagem de 22 estudantes. As aulas iniciaram, cumprindo nosso calendário escolar, em 25/02/2019.

A maioria dos alunos da turma do $4^{\circ}$ ano A já são "velhos" conhecido entre si, muitos deles estão juntos desde o $1^{\circ}$ ano, eu, Minecraft e mais uma menina somos novos por aqui.

No primeiro dia, recebi Minecraft, acompanhando-o sua monitora da inclusão, uma estudante do curso de graduação em Psicologia na FURG. Essa monitora o acompanha desde o ano de 2018. Eles já possuíam vínculo e eu quase não conseguia criar laços com ele, sentia até medo ao pensar no dia que ela não fosse estar presente na minha sala de aula. 
Desde o inicio, o aluno mostrava-se muito inquieto e com muita dificuldade em obedecer aos meus pedidos, sempre fazendo o que gostava e desafiando o tempo todo. Não demonstrava interesse em nada de sala de aula, nem acompanhava o ritmo de ler e escrever palavras. Com seus colegas, apenas com dois, um menino e uma menina mostrava amizade, com os demais agia sempre os desafiando. Pra mim era muito difícil ter esse aluno entre os demais, eu disputava com ele a minha sala de aula.

Numa determinada situação em meados de março, Minecraft teve um surto em sala de aula, todas as demais crianças precisaram ser retiradas de sala de aula e as profissionais da Sala de Recursos da escola deram ao menino todo o apoio. Também foi necessário acionar os profissionais da saúde (UBSF) que ficam ao lado da escola, que logo nos atenderam, avaliaram o menino e perceberam a necessidade de acionar a ambulância. Desde o inicio do surto, os familiares do Minecraft estiveram presentes e não conseguiam diálogo com ele. O menino tem indicativo de Transtorno Opositivo Desafiador.

O Transtorno Opositor Desafiador ou Transtorno Desafiador de Oposição é um padrão de comportamento chamado de disruptivos, forma de liberar impulsos agressivos, tipo de comportamento que prejudica as pessoas com as quais se convive, criando conflitos não só com as figuras que representam autoridade como também em relação às regras pré-estabelecidas. Entretanto, este transtorno acaba prejudicando o próprio autor por toda a rejeição que se cria em torno dele (SILVA, 2017. p. 15).

Minecraft retornou as atividades escolares alguns dias depois.

Na mesma semana que ele voltou, a monitora ausentou-se por motivos pessoais e eu me vi sem ela e muito assustada com esse aluno.

Medo, essa é a palavra, e muitas inquietações, como vou fazer? Não sei lidar com ele! Neste momento me dei conta que eu não conhecia meu aluno.

Apoiada pela direção da escola e coordenação pedagógica, outra professora tomou a frente da minha turma, aplicando meu planejamento e eu fui atender e conhecer Minecraft. Conversamos muito, jogamos, brincamos e nosso laço começou a nascer. Desde esse dia, Minecraft tornou-se mais afetuoso comigo.

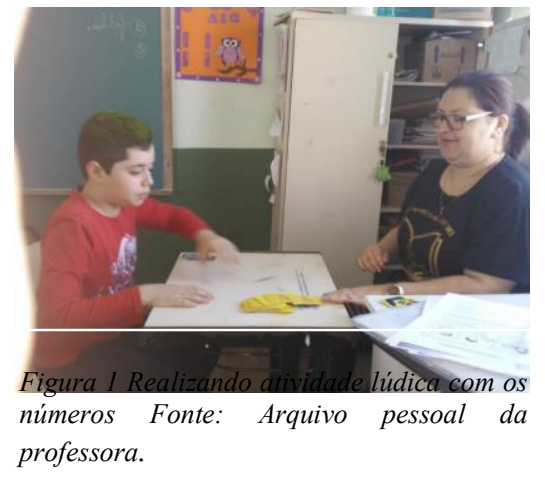


Muitos outros dias minha monitora precisou ausentar-se por motivos pessoais e nos tornamos amigos.

Numa determinada manhã, ao chegar à sala de aula, ele me pediu para brincar de “o mestre mandou”, em outro tempo eu negaria, estaria ansiosa em colocar a data no quadro e iniciar minha aula, mas desta vez, sem abrir nenhuma mochila, começamos a brincar.

Toda a turma participou e foi uma forma diferente de iniciarmos nossa manhã.

Foi marcante, para nós dois, eu estava disposta a mudar.

Depois dessa brincadeira, minha aula fluiu inclusive com a participação dele. Neste dia conversamos sobre o sistema monetário. Levei encartes e ele participou da atividade com muita tranquilidade e inclusive em dupla com um colega.

Mesmo com a presença da monitora, o menino e eu estávamos diferentes, com mais amizade, afeto e respeito entre nós e os colegas da turma.

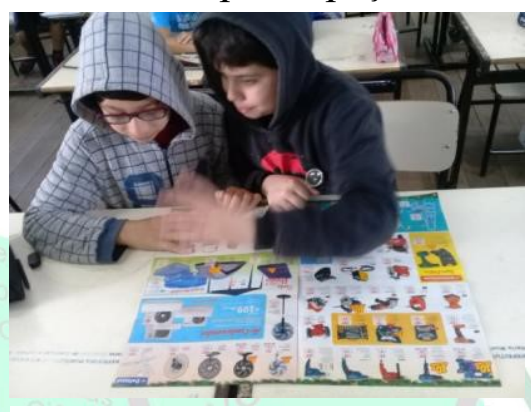

Figura 2 Minecraft realizando atividades do sistema monetário

Cada dia eu estava aberta a dialogar, escutá-lo e Fonte: Arquivo pessoal da professora não mais sair ditando as regras, mudou a minha posição...

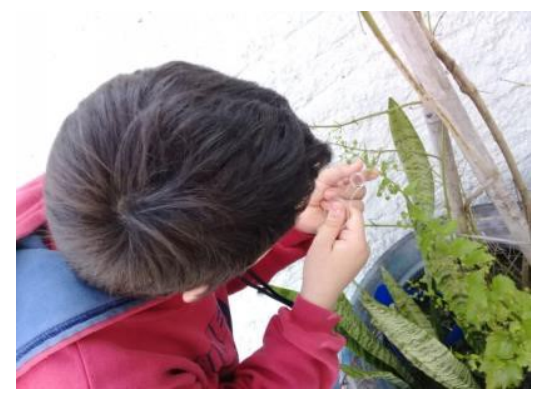

Figura 3 Observação da natureza na escola.Fonte: Arquivo pessoal da professora

Cotidianamente ele me apresentava algo diferente, tivemos momentos de pesquisadores, de construção de esqueleto, de observadores da natureza, de jogar, de escrever palavras, de brincar com os números e de socializar com os demais colegas da turma.

Nossa amizade cresceu professora assumisse minha turma, Minecraft já conseguia entender alguns combinados e de forma harmoniosa ficávamos todos juntos na turma.

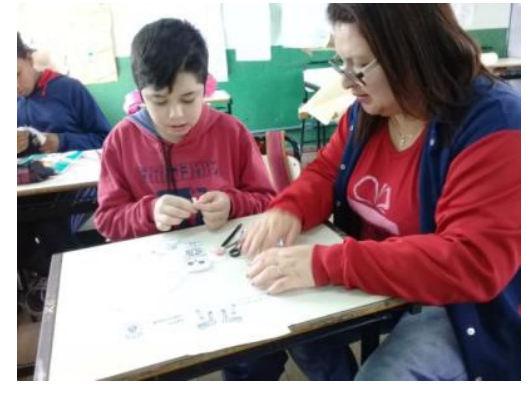

Figura 4 Corpo humano, ossos. Fonte: Arquivo pessoal da professora 
Diante dos avanços dele percebi que já eram possíveis novas aventuras, assim Minecraft aprovou para o $5^{\circ}$ Ano, quanta alegria, para todos nós, escola, família!

\section{NUM DIÁLOGO COM AUTORES: ANÁLISE REFLEXIVA}

Essa experiência relatada acima nos possibilita tratar de assuntos muito necessários à prática educacional.

Minecraft tem o direito a uma prática diária na sala de aula seja inclusiva e que o meu olhar de professora seja de acolhida e de respeito a este sujeito.

Em relação á prática pedagógica, quando o professor não reconhece as diferenças em sala de aula e suas ações partem de uma prática homogeneizadora, ele opera na produção das desigualdades, pois exclui os alunos que se encontram fora dos padrões considerados "toleráveis", homogêneos e idealizados. Tais práticas subjacentes ás ações dos professores negam direitos de aprendizagem dos seus alunos, pois cada um deles é diferente. (Brasil, caderno 1 PNAIC, 2015, p. 57)

Nossos primeiros contatos de resistência dele a mim e de insegurança minha com relação a ele foi sendo superado à medida que eu enquanto professora, fui modificando a minha prática. Foi só a partir disso que meu fazer docente deixou de ser homogeneizador e o menino passou a ser integrante da minha sala de aula.

Eu trago no inicio da na minha escrita alguns indícios de medo de perder o controle, pois confesso que "eu disputava com ele a minha sala de aula". Reflito agora que na verdade não disputava com ele um espaço, ele queria na verdade que o acolhesse e isso foi acontecendo na medida em que fui entendendo que fazer a inclusão na sala de aula, precisou que eu incluísse primeiro comigo, "impor um modo de ser e não reconhecer a identidade do Outro é uma das questões que pode dificultar a inclusão na escola" (Brasil, caderno 1, PNAIC, 2015 pg.58).

Todo esse entendimento de inclusão, de respeito também precisa ser da escola, dos gestores. Uma escola que não entende um caso como o da Minecraft, não será acolhedora, não tratará a família com todo o respeito e apoio que ela precisa.

Nesta instituição de ensino em que eu sou docente, se tem entendimento, clareza sobre a inclusão. Temos profissionais capacitados e atender alunos com as mais variadas necessidades. E isso foi fundamental para que eu me sentisse segura a incluir o menino 
na minha docência. Sempre em diálogo com as profissionais da Sala de Recursos e com a coordenação da escola, trocando ideias, desabafando meus medos e recebendo apoio profissional embasado em muita teoria.

O trabalho do professor em sala de aula, evidentemente, depende da concepção que se tenha da tarefa social da escola. O que se espera da escola? Quais suas funções sócias? A questão do que fazer passa, portanto, antes de mais nada, pela postura do professor (e da escola) pela maneira como o professor entende seu papel. (VASCONCELLOS. 2004, p.39)

O professor ao ter consciência de seu papel social na escola e na vida estudantil de seus alunos passa então a modificar sua ação pedagógica, pensando e planejando atividades que sejam inclusivas.

Quando estamos dispostos a incluir, estamos dispostos a aprender.

Eu vivenciei disto com Minecraft e conto isto quando, na minha narrativa, no passar dos dias digo que "Sem sombra de dúvida este aluno teria muito e me ensinar." E, como me ensinou, compreendi o que é a inclusão, a enfrentar os medos e a ressignificar minha prática.

Sobre isso, Paulo Freire (1996) que me acolhe em suas palavras quando diz que "Quem ensina aprende ao ensinar e quem aprende ensina ao aprender". E fui cotidianamente aprendendo, pois "Cada dia eu estava aberta a dialogar, escutá-lo e não mais sair ditando as regras, mudou a minha posição...” essa mudança de posição modifica diretamente a minha sala de aula, meu planejamento e minha relação com Minecraft," o modo como os professores percebem os alunos interfere fortemente no planejamento das aulas e nos encaminhamentos a serem realizados. " (Brasil, caderno 1, PNAIC, 2015 pg.58)

Diante das modificações na minha prática pedagógica, do entendimento sobre á inclusão, no final do ano letivo o menino obtém aprovação. Foi um ano letivo de muita aprendizagem para todos; minha, de Minecraft e as demais crianças da turma.

A prática a ser alcançada e desenvolvida é a prática pedagógica significativa. Dialeticamente, o professor deve confrontar realidade e objetivo, visando a realização de uma prática consciente, ativa e transformadora, que supere o viés reprodutivista (fazer acriticamente o que sempre fez) ou idealista (ficar na ideia e não alterar a realidade) (VASCONCELLOS, 2004, p. 77). 
Foi um caminho longo e com muito aprendizado, em nenhum momento foi fácil, precisei vencer medos e também da ajuda dos profissionais da escola, diante disso posso afirmar que uma prática ativa e transformadora é possível em uma escola pública.

\section{AMARRANDO AS IDEIAS.}

Ao longo desta narrativa apresentei minha experiência com MInecraft, apresentei os desafios da inclusão e todos os avanços que fizemos juntos.

É imprescindível destacar a importância do planejamento frente a desafios como este, em que tenho o aluno como sujeito principal e que a partir dele as atividades podem acontecer. Esse planejamento precisa priorizar o potencial de cada estudante fazendo com que o mesmo possa se desenvolver dentro das suas possibilidades, tornando-o um sujeito socialmente participativo.

Penso também que ao encerrar esta narrativa, preciso apontar para as políticas públicas para a inclusão, é importante que cada vez mais se dialogue sobre este assunto, que se tenham profissionais capacitados para atuar tanto em sala de aula quanto nos outros espaços da escola com alunos inclusos.

Reafirmo também a importância da Sala de Recursos como apoio ao professor frente ao desafio da inclusão. Os profissionais que atuam neste espaço, além de contribuir com sua experiência também oferecem material pedagógico, o próprio espaço físico, e o atendimento profissional no contra turno, todas estas ações que fazem a diferença na escola para o professor e principalmente para o aluno.

Outro ponto a destacar desta experiência é o papel da Direção e Coordenação Pedagógica da escola que compreendem a inclusão e tem um olhar acolhedor com o professor e com o aluno. Facilitando que as atividades planejadas pelo professor aconteçam, possibilitando que outro professor trabalhe junto, permitindo assim a docência compartilhada.

Sobre essa docência compartilhada posso dizer que foi importante para que eu e Minecraft tivéssemos tranquilidade em criar nosso laço e estabelecer um vinculo afetivo que refletiu em todo nosso crescimento. 
Eu não tinha em sala de aula somente ele, tinha também 21 alunos que precisam de atenção e de numa aula de qualidade com um profissional dedicado tanto quanto eu estava com Minecraft.

Tivemos dias difíceis, mas não posso terminar aqui sem afirmar que nós crescemos.

Os medos existiram, foi o que contei lá no início, mas, “Assumir o medo é não fugir dele, é analisar a sua razão de ser, é medir a relação entre o que o causa e a nossa capacidade de resposta", Freire (1997).

Nossa profissão tem disto, e precisa que analisemos cotidianamente cada situação, cada aluno para que possamos superar os medos, vencer os desafios e fazer uma docência inclusiva com muita boniteza e esperança.

\section{REFERÊNCIAS}

BRASIL. Pacto Nacional pela Alfabetização na Idade Certa. Currículo na perspectiva da inclusão e da diversidade: as Diretrizes Curriculares Nacionais da Educação Básica e o ciclo de alfabetização. Caderno 01/Ministério da Educação, Secretaria da Educação Básica. Brasília, 2015.

DA SILVA, Tatiane Cristina Gonçalves. Transtorno Opositor Desafiador- Como enfrentar o TOD na escola. Monografia apresentada ao Instituto A Vez dos Mestres, Professora Orientadora: Fabiane Muniz, UNIVERSIDADE CÂNDIDO MENDES, Rio de Janeiro, 2017.

Disponível em:

https://www.avm.edu.br/docpdf/monografias_publicadas/posdistancia/53309.pdf Acesso em 04/11/2020 ás 20h.

FREIRE, Paulo. Pedagogia da autonomia: saberes necessários á prática educativa. São Paulo. Paz e Terra, 1996.

FREIRE, Paulo. Professora sim, tia não: Cartas a quem ousa ensinar. São Paulo-SP. Olho Dágua, 1997.

VASCONCELLOS, Celso dos Santos. Construção de conhecimento em sala de aula. São Paulo, Libertad, 2004. 